\title{
A Study On The Influence Of Sodium Salt Solution On The Atterberg Limits And Swelling Of Bentonite Clay
}

\author{
Saurabh Kumar*1, Dr. Prashant Garg ${ }^{*^{2}}$, Amandeep Singh ${ }^{* 3}$ \\ ${ }^{*}$ MTech. Student, Department of Civil Engineering, Guru Nanak Dev \\ Engineering College, Ludhiana, Punjab, India
*2,3 Assistant Professor, Department of Civil Engineering, Guru Nanak Dev
Engineering College, Ludhiana, Punjab, India

\begin{abstract}
Due to industrialization and subsequent rise in urbanisation, our groundwater system and geoenvironmental reserves are getting degraded due to detrimental effects of industrial wastes discarded off into the geo-environment. Basic components like water, air and soil all get degraded resulting unacceptable loss of their natural virtues like purity, renewability, stability, sustainability and tolerability. Major industrial effluents like salt solutions, chemicals, artificial dyes, heavy metals, pharmaceutical residues and sewages etc., are posing the major problems for the ecosystem and their subparts. Since, bentonite clay has peculiar characteristics of high swelling and high pollutant absorbing capacity along with low hydraulic conductivity, it is used as a geotechnical clay liner. However, the geotechnical parameters of bentonite get affected on interaction with cations present in salt solutions. This investigation was carried out in order to observe the influences of salt solutions on bentonite and the results obtained depicts that the varying salt concentrations have a definite influence on Atterberg limits, swelling of bentonite.
\end{abstract}

Keywords: Bentonite, Salt solution, Atterberg limits, Swelling, Geo-environment

\section{INTRODUCTION}

With the advent of Industrial Revolution in late $18^{\text {th }}$ century, the continued and accelerated urbanisation rose the economy of few capitalist nations but on other side, it globally downgraded the nature and its components at extreme. Many folds increment in municipal solid wastes bring it under one of the most serious geo-environmental concern in both developing and developed nation. These solid wastes, after undergoing biological and physio-chemical changes release various salts in form of leachate and undergo mixing with trickling rain water then movement towards the runoff then to groundwater, interaction with different soil components and finally contaminates it. 
Bentonite clay is essentially, an impure clay exists as an aluminium phyllosilicate absorbent form, produced as volcanic ash deposits at wet sites of shallow depth. Since, bentonite exists naturally, hence its chemical, mineralogical and size distributional characteristics of grains vary significantly source or location-wise. Multiple parameters as type and amount of montmorillonite, surface area, surface charge densities and exchangeable cation type influence the geotechnical behaviour of bentonite considerably.

Montmorillonite is the primary mineral of bentonite clay. Expansive and Contractive behaviour shown by montmorillonite is due to the weak van-der- Waal's attraction in between the layers allowing the polar molecules or hydronium ions to ease their movement causing significant swell or shrink. On mixing of dry bentonite in water, water moves towards the montmorillonite particles so as to hydrolyse the cationic and elemental sheets surface.The hydration caused by intermixing of water and sodium montmorillonite, the formation of viscous and thick diffuse layers of ions around the layer get occurred which results in swelling of montmorillonite particles upto an extent where the full separation of sheets is realised.

Diffuse double layer's formation characterises the interacting mechanism in between the clay mineral and ions present in salt solution. There is an equilibrium state in dry condition where the anions get balanced by the exchangeable cations of sodium, magnesium, calcium and potassium which surrounding them and bonded together by electrostatic attractive forces. The electro-negativity of clay get neutralised by excessive cations present and salts get precipitated by result of associated anions.

In Geotechnical field, Soil has been treated as the most fundamental determinant to be investigated, upon which almost all the superstructures and foundations lie which means the poor soil like bentonite clay can create a huge problem due to their contractive and expansionist behaviour. The clay mineralogy, exchangeable cation type and pore-water mechanism have great influence on the thickness of double diffused layer. Along with their individual behaviour, their surroundings and interacting particles and ions like Salt solutions also complement the whole geotechnical scenario.

\section{METHODOLOGY}

For investigating influence of salt solution on bentonite clay, five different salt concentrations were prepared in this study that are $0.342 \mathrm{M}, 0.684 \mathrm{M}, 1.025 \mathrm{M}, 1.368 \mathrm{M} 1.709 \mathrm{M}$ molar solution. Untreated or deionised water is represented by $0 \mathrm{M}$ salt solution. Salty pore fluids were prepared by using commercial $\mathrm{NaCl}$ crystals. Here, for $0.342 \mathrm{M}$ of salt concentration means 2 
grams of $\mathrm{NaCl}$ in 100 millilitres of de-ionised or untreated water. The specimen was prepared as such:

I. Over-drying of bentonite clay.

II. The sample which was ovendried, now mixed with $\mathrm{NaCl}$ concentrations viz. 0.342M, $0.684 \mathrm{M}, 1.025 \mathrm{M}, 1.368 \mathrm{M} \& 1.709 \mathrm{M}$. Take sample 1 as (Bentonite+ $0 \mathrm{M} \mathrm{NaCl}$ ) or (Bentonite + DI Water) and so on till 1.709M NaCl addition.

III. Dried mixes which were formed, being added with water in order to form workable or consistent blend.

IV. The prepared mixes were kept in oven dried after keeping the mixes aside for 1 day or $24 \mathrm{hrs}$.

V. The prepared mixes were now ready for study purposes as test specimen.

VI. Multiple experiments like casagrande's test, thread-rolling test and differential free swelling tests were performed in order to investigate the atterberg limits and swelling behaviour of bentonite clay on salt addition.

VII. Finally, evaluation of the liquid limit, plastic limit, plasticity index and differential free swell percentage against elapsed time.

\section{MATERIALS AND EXPERIMENTAL WORK}

Bentonite clay is utilised here for investigation purpose which was procured from a seller based in Focal Point, Ludhiana (Punjab). The origin place of this bentonite was Jamnagar, Gujarat.

\section{BENTONITE CLAY}

Bentonite clay is essentially,an impure clay exists as an aluminium phyllosilicate absorbent form, produced as volcanic ash deposits at wet sites of shallow depth in different locations worldwide. The continued pyroclastic flow after volcanic eruption leads to the successive phenomena of hydrothermal alteration due to presence of hydrothermal solutions and diagenetic alteration in favourable temperature, pressure and time.

\section{NaCI SALT SOLUTION}

Sodium chloride which is popularly known as common or table salt has white colour, obtained from seawater on crystallisation and evaporation. Impurity is removed by refining and finally, available in market as crystals. It shows hygroscopic and deliquescent behaviour that's why it absorbs and retains moisture obtained from surroundings. Salty pore fluids were prepared by using commercial $\mathrm{NaCl}$ crystals. 
Experiments which were conducted for present study :

- Casagrande's test for liquid limit

- Thread rolling test for plastic limit

- Determination of plasticity index

- Differential free swelling test

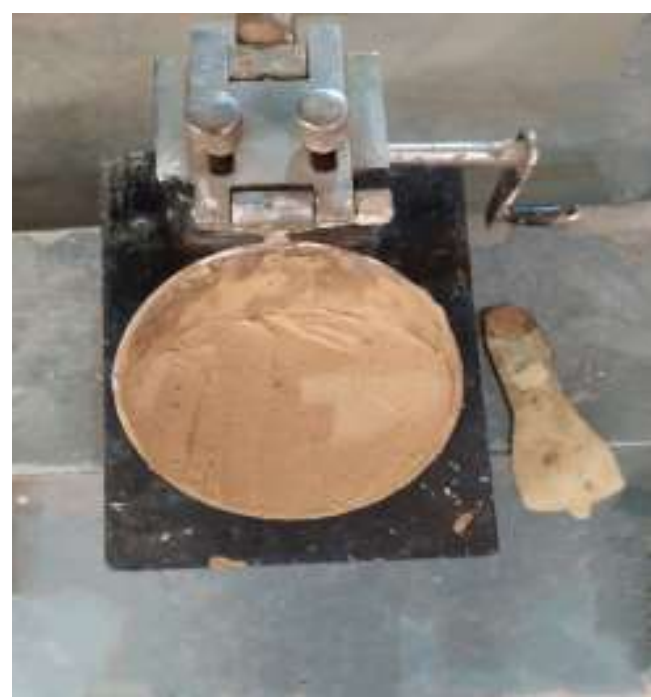

Fig.1 Casagrande's apparatus

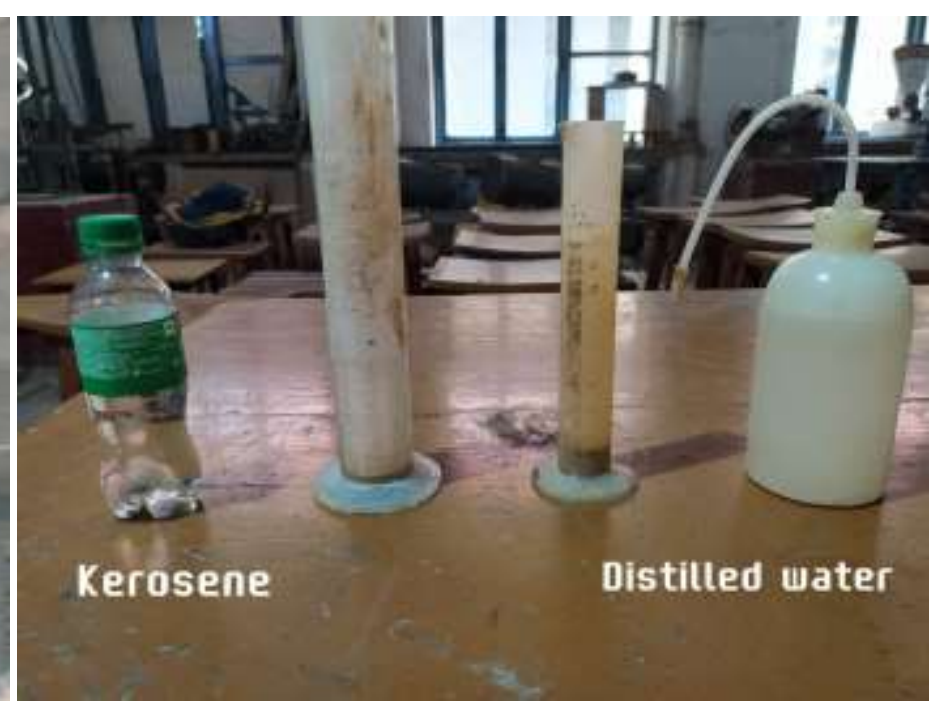

Fig.2 Differential free swelling test

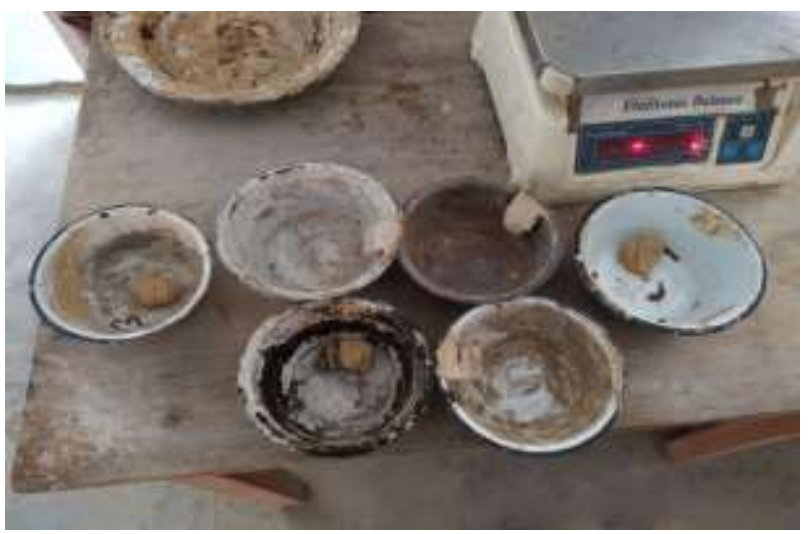

Fig.3 Oven-dried bentonite clay

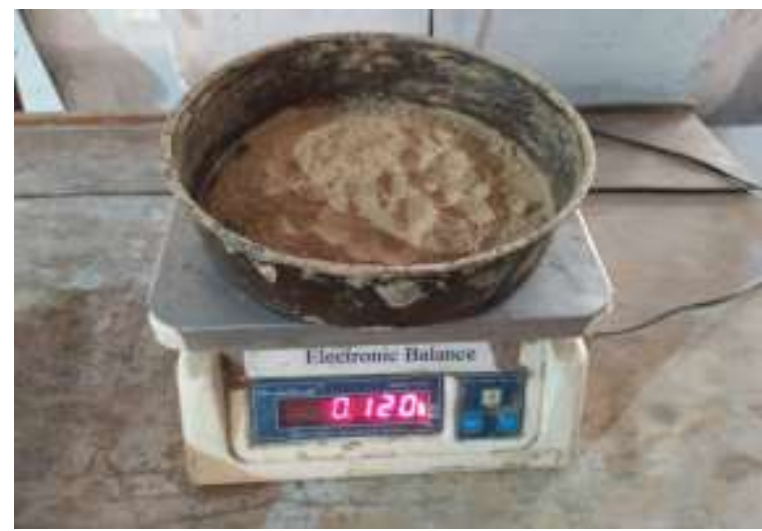

Fig.4 Bentonite clay sample for weight

\section{RESULTS AND DISCUSSION}

\section{Properties of bentonite clay}

For the evaluation of Atterberg's limits,plasticity index, differential free swell, optimum moisture content(OMC), maximum dry density(MDD), unconfined compressive strength (UCS), undrained cohesion $\left(\mathrm{C}_{\mathrm{u}}\right)$, angle of internal friction $(\otimes)$ and califorfornia bearing strength (CBR), mutiple tests were conducted where liquid limit is evaluated to be greater than $50 \%$, 
which means the bentonite clay can be classified as highly plastic and highly compressible as I.S soil classification (I.S.S.C). The experimental results are tabulated below in table 1.

Table 1. Geotechnical charracteristics of untreated bentonite clay.

\begin{tabular}{|c|c|}
\hline Geotechnical parameters & Test results (units) \\
\hline Liquid limit & $210 \%$ \\
\hline Plastic limit & $35.5 \%$ \\
\hline Plasticity Index & $173.5 \%$ \\
\hline Soil type (as per I.S.S.C) & $\mathrm{CH}$ \\
\hline Differential free swell & $78 \%$ \\
\hline Optimum moisture content & $29.5 \%$ \\
\hline Maximum dry density & $1.22 \mathrm{~g} / \mathrm{cm}^{3}$ \\
\hline Unconfined compressive strength & $240 \mathrm{kN} / \mathrm{m}^{3}$ \\
\hline Undrained cohesion & $120.68 \mathrm{kN} / \mathrm{m}^{3}$ \\
\hline Angle of internal friction & $6.98^{\circ}$ \\
\hline California bearing ratio & $1.5 \%$ \\
\hline
\end{tabular}

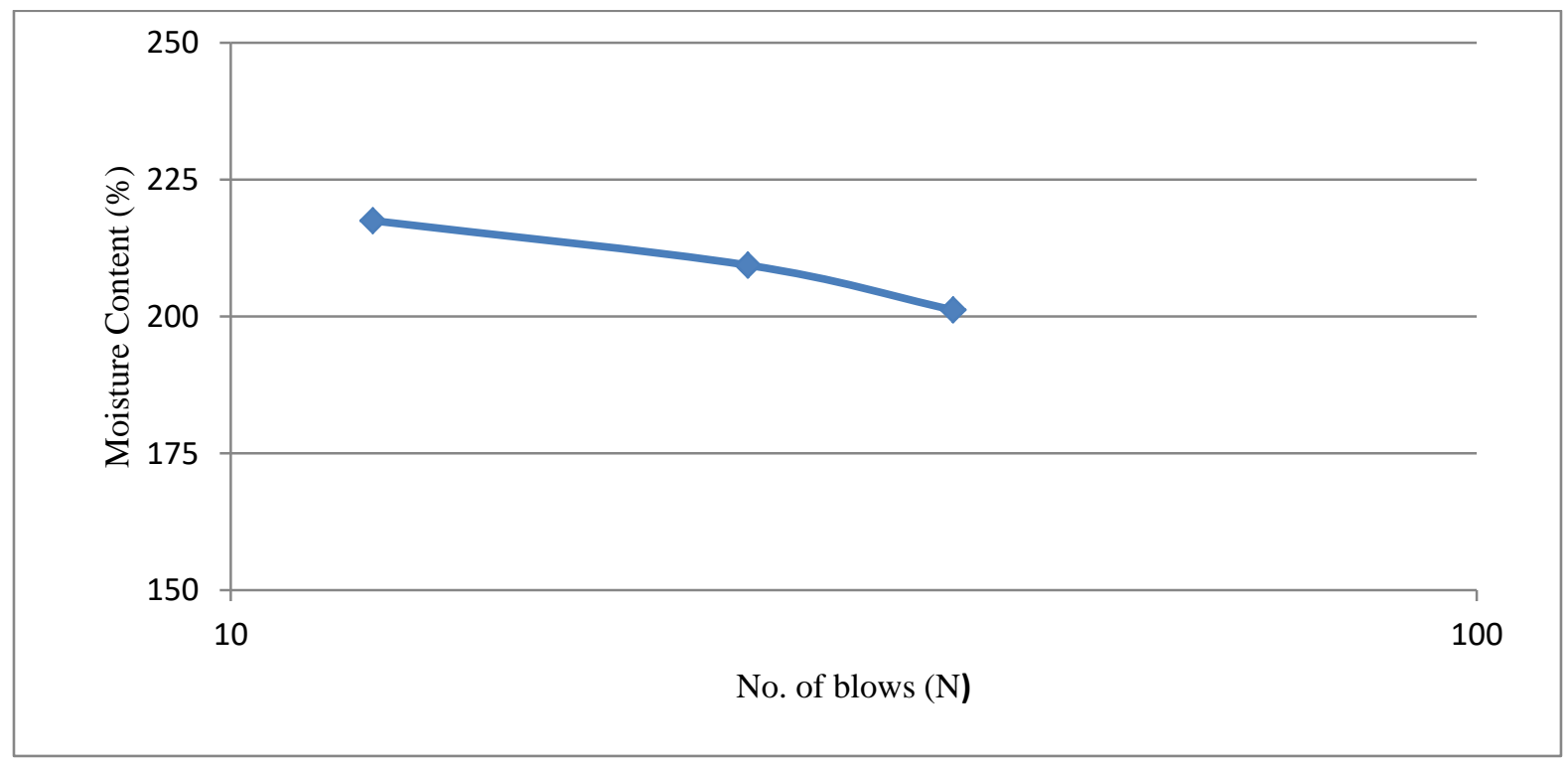

Fig.5 A plot in between moisture content and no. of blows for untreated bentonite clay. 


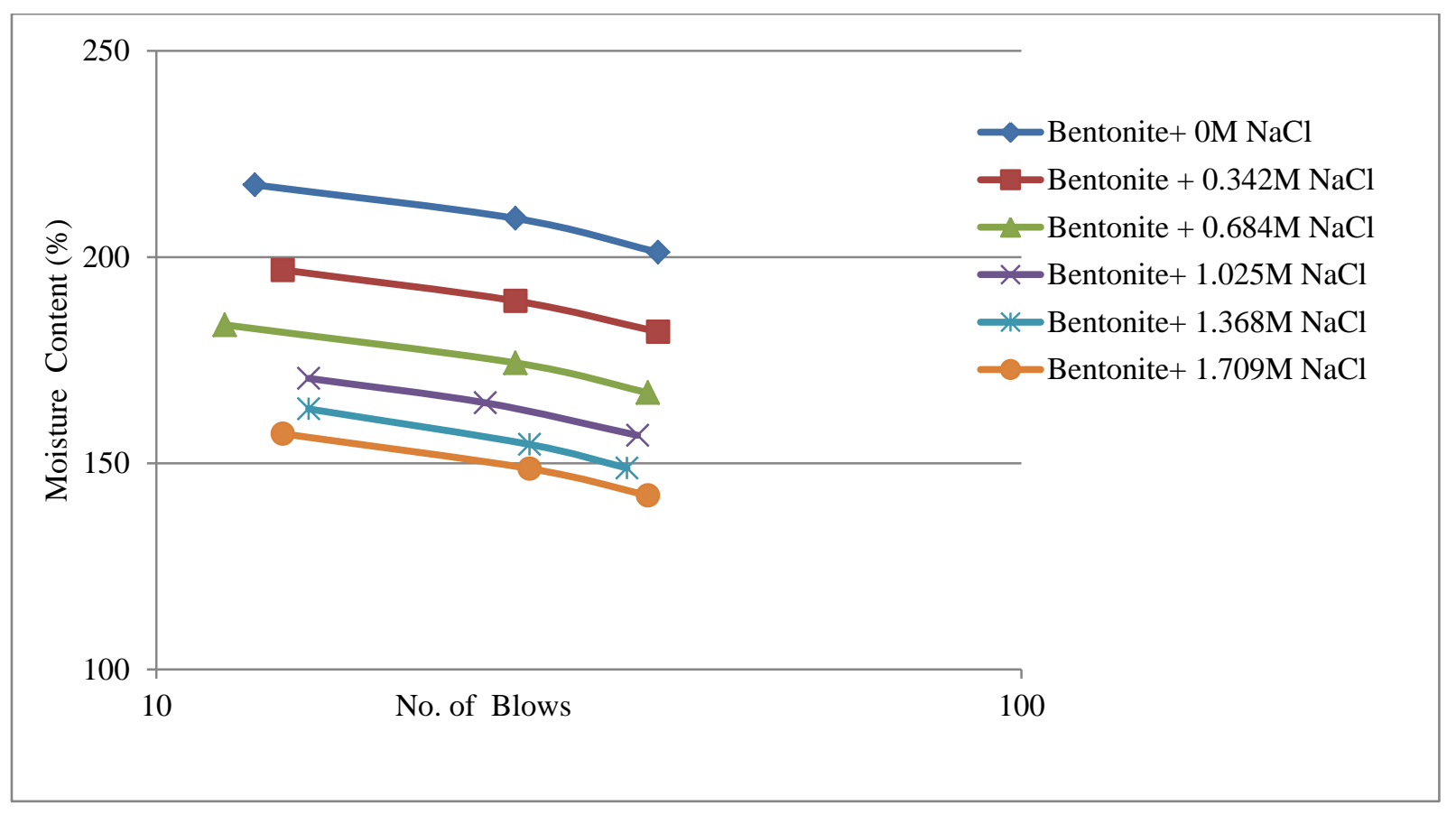

Fig.6 Plots in between moisture content and no. of blows of bentonite at varying $\mathrm{NaCl}$ concentrations.

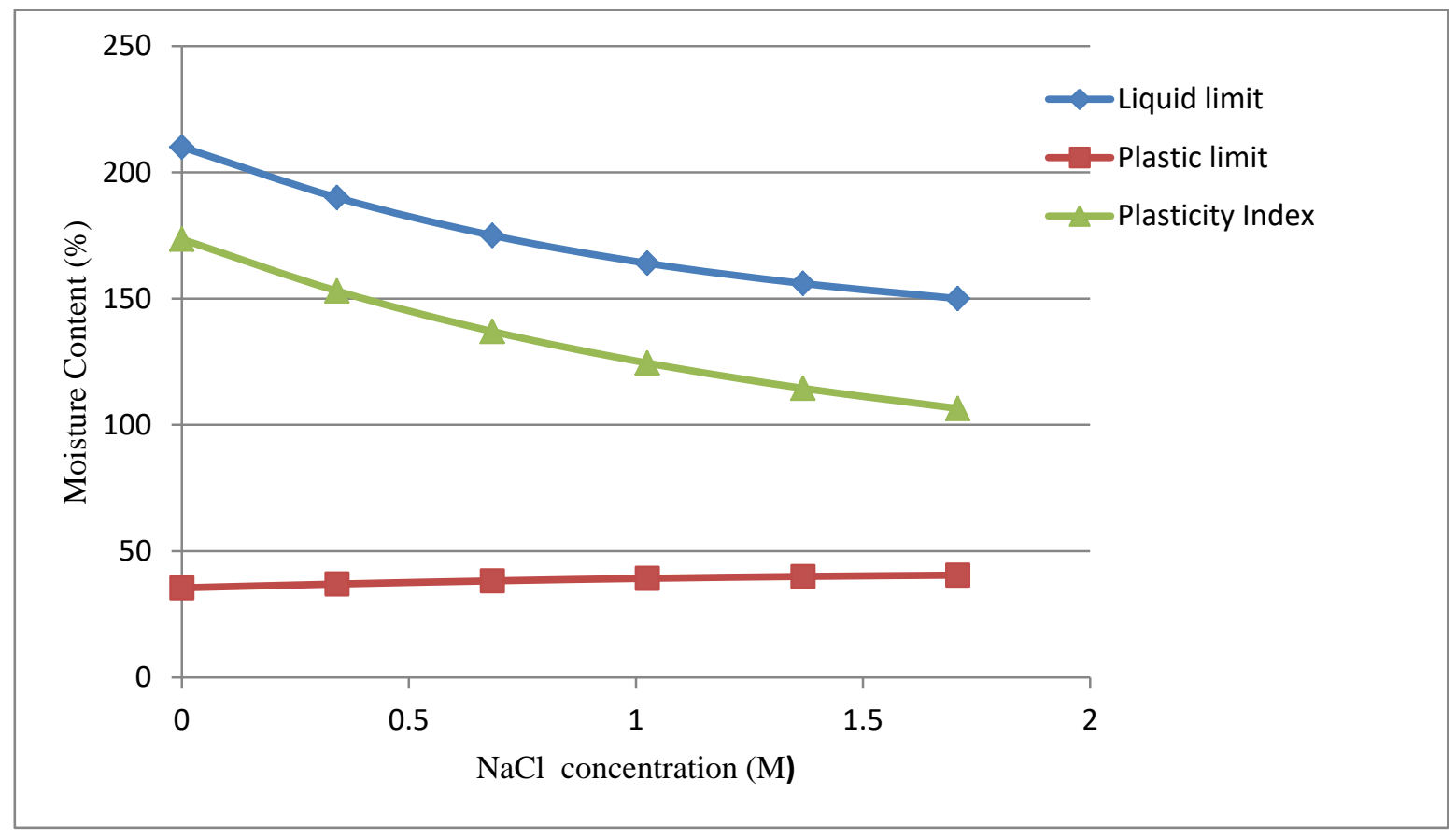

Fig.7 Plots of Atterberg limits variation with varying $\mathrm{NaCl}$ concentrations.

For enhancement in $\mathrm{NaCl}$ concentration, the inter-particle repulsive force gets decreased which provides the ease in free movement of soil particles, at lower moisture contents and shorter inter-spaces between the particles, resulting lowering in liquid limit. 
The moisture content's lower boundary at which the clay still manifests its plastic characteristics is termed as plastic limit. It marginally increases from $35.5 \%$ at DI water to $40.5 \%$ at $1.709 \mathrm{M} \mathrm{NaCl}$ solution. For orienting in new position in the plastic phase, the particles of soil should have to ability to move freely or slide pasting on another, so that the new position can be attained; however, there should have lower cohesion between inter-molecules to allow this free movement and to hold the soil particles strongly enough, so that the new position can be retained in equilibrium.

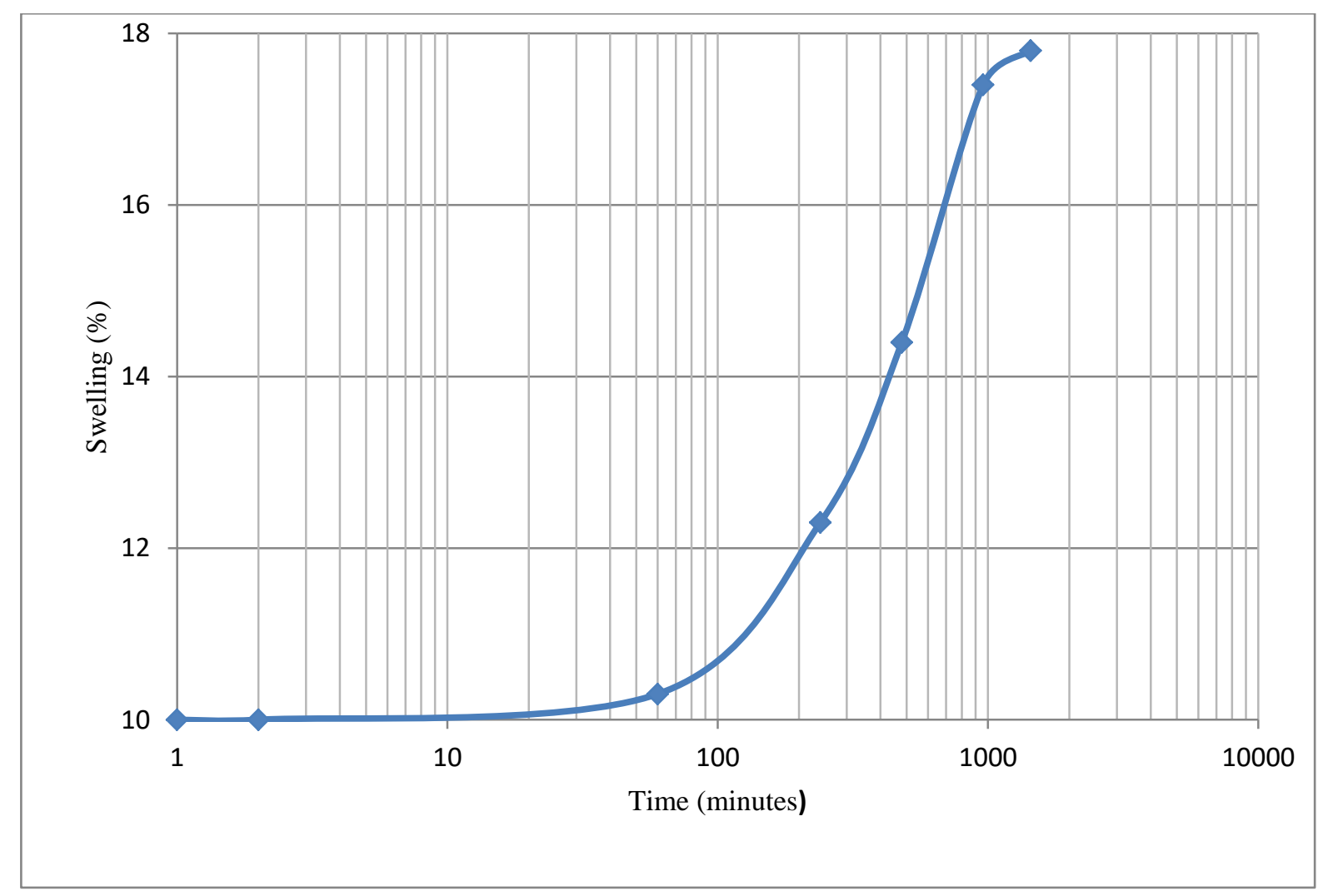

Fig.8 Time-swelling plot for untreated bentonite clay.

The free swelling plot for untreated bentonite sample is represented in Fig.4.4 which depicts that after 1440 minutes or $24 \mathrm{hrs}$ of equilibrium time, the swelling percentage gets increased from $0 \%$ ( just after putting bentonite in distilled water) to $78 \%$ ( till 1440 minutes). The higher swelling percentage in $\mathrm{NaCl}$ sol. is due to occurrence of both inter-crystalline and osmotic swelling and consequently, size in between the inter-layer spacing gets larger resulting more swelling. 


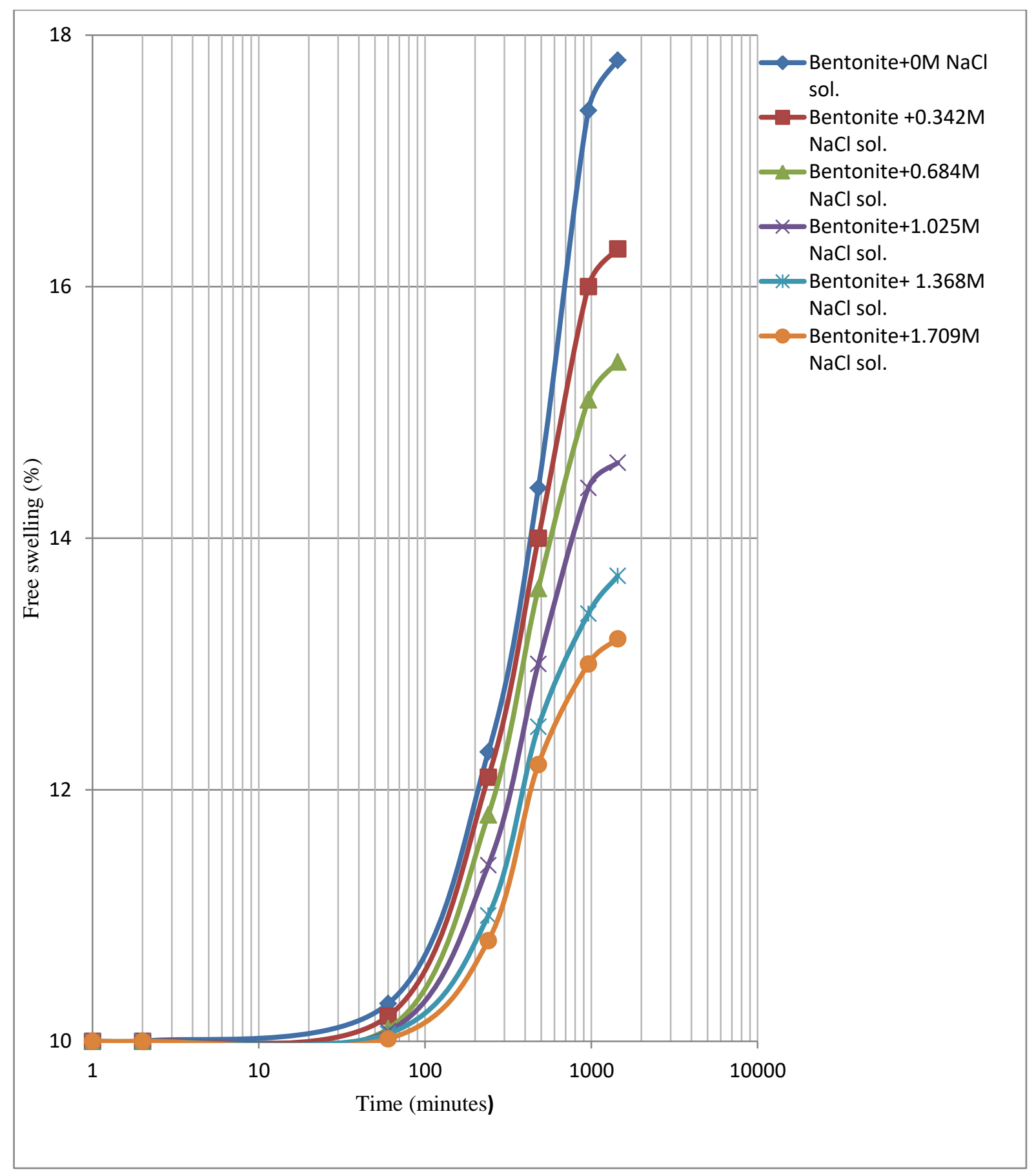

Fig.9 Time-swelling plots of bentonite at varying $\mathrm{NaCl}$ concentrations.

This swelling-elapsed time plot traces the ' $S$ ' curve irrespective of saturating fluid type or initial compaction characteristics. The plot depicts slow increase in swelling characteristics of bentonite initially, gets steeper in intermediate and finally approaches to asymptotic value.

Initial and secondary swellings have marginal increment while primary has the considerable swelling. This may be due to matric suction dissipation rate which also, causes the independency on $\mathrm{NaCl}$ concentrations. Just because of diffusion mechanism, the secondary swelling processes at slower pace. Longer duration is acquired in order to complete the secondary swelling because of its dependency on adsorption- desorption mechanism. 


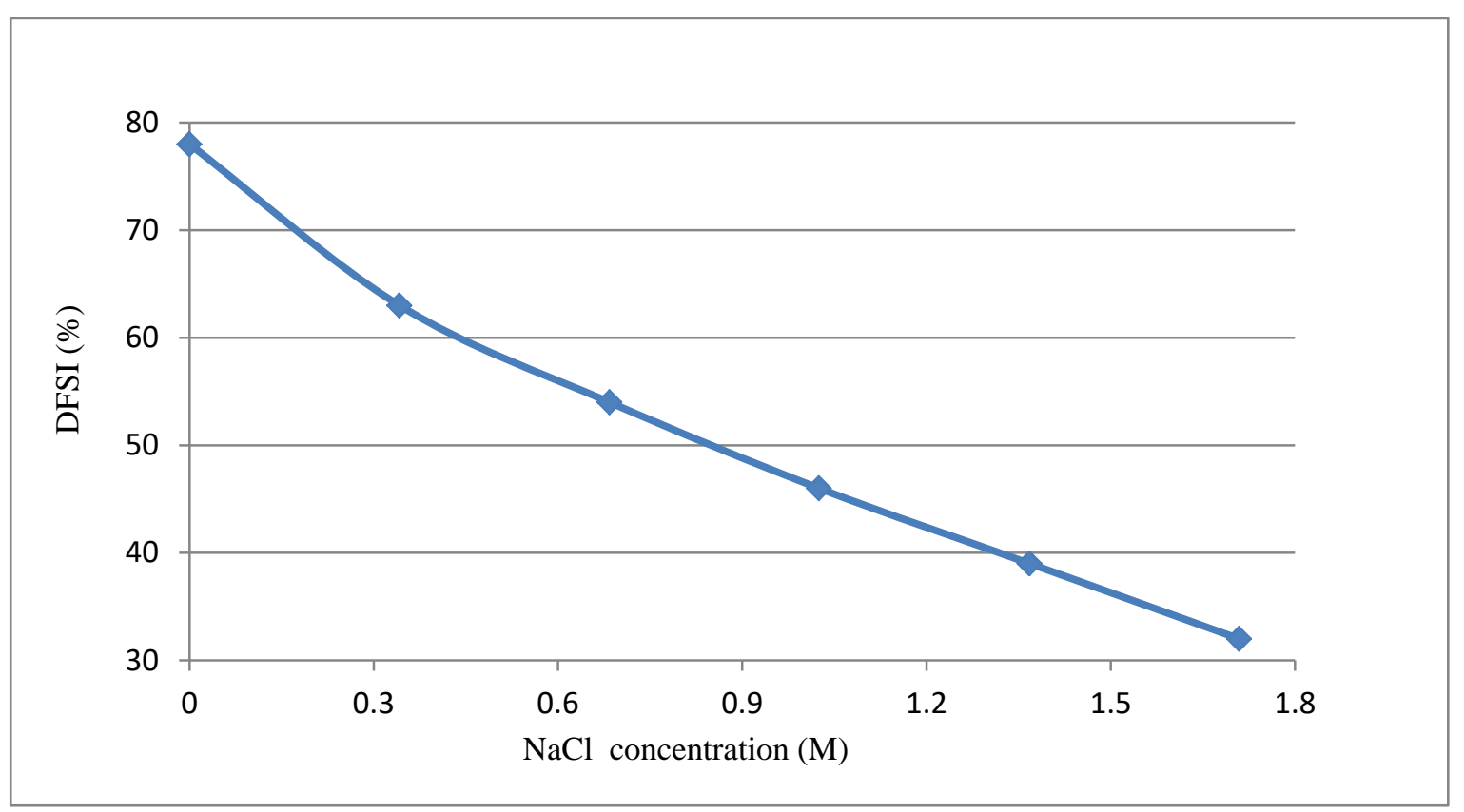

Fig.10 Relative decrease in free swelling percentage at varying $\mathrm{NaCl}$ concentrations.

\section{CONCLUSIONS}

The present study was carried out to explore the influences of sodium salt solution on the behaviour of bentonite clay. Bentonite clay was investigated for its changing behaviour in Atterberg limits and free swelling due to existence of sodium salt concentrations at varying proportions. The concluded results are:

- The liquid limit gets decreased significantly due to insertion of $\mathrm{NaCl}$ solution. The liquid limit value for untreated bentonite was found to be $210 \%$ which gets decreased significantly upto $164 \%$ till $1.025 \mathrm{M} \mathrm{NaCl}$ conc. and then marginal decrease upto $150 \%$ till $1.709 \mathrm{M} \mathrm{NaCl}$ concentration.

- The plastic limit of bentonite clay influenced with sodium salt solution gets increased marginally from $35.5 \%$ at $0 \mathrm{M} \mathrm{NaCl}$ sol. to $41 \%$ at $1.709 \mathrm{M} \mathrm{NaCl}$ solution. There is no significant rise in plastic limit values from $0 \%$ to $10 \% \mathrm{NaCl}$ addition.

- In similar way, the plasticity index gets increased from $173.5 \mathrm{M}$ at $0 \mathrm{M} \mathrm{NaCl}$ solution to $106.5 \%$ till $1.709 \mathrm{M} \mathrm{NaCl}$ concentration.

- The differential free swelling percentage for untreated bentonite clay was found to be $78 \%$, it gets decreased as the $\mathrm{NaCl}$ concentration rises. DFSI\% gets decreased from $78 \%$ at $0 \mathrm{M} \mathrm{NaCl}$ conc. to $46 \%$ at $1.025 \mathrm{M} \mathrm{NaCl}$ conc. and finally reached upto $32 \%$ at $1.709 \mathrm{M} \mathrm{NaCl}$ concentration. 
- From time-swelling plot for treated and untreated bentonite clay, it can be concluded that for initial 1-10 minutes, there was almost negligible swelling. The initial swelling starts increasing marginally till nearly 100 minutes.Then, significant increase in swelling from 100 minutes till nearly 1000 minutes. More than $95 \%$ of the swelling parts were completed till 1000 minutes. This time zone corresponds to primary swelling and finally, again it gets swell but at marginal rate and approached to an asymptotic curve, it would take longer duration for the completion of secondary swelling.Lesser the amount of $\mathrm{NaCl}$ sol. in bentonite, steeper rise in the swelling curve.

\section{REFERENCES}

1) Alther, G., Evans, J.C., Fang, H.Y. and Witmer, K. (1985). Influence of inorganic permeants upon the permeability of bentonite, Hydraulic barriers in soil and rock, ASTM STP 874, 64-73.

2) Komine, H. and Ogata, N. (1996). Prediction for swelling characteristics of compacted bentonite, Canadian Geotechnical Journal, 33,11-22.

3) Malik, M., Mustafa, M. A. and Letey, J. (1992). Effect of mixed Na/Ca solutions on swelling, dispersion, and transient water flow in unsaturated montmorillonitic soils, Geoderma, 52, 17-28.

4) Mishra, A.K., Dhawan, S. and Rao, S.M. (2008). Analysis of swelling and shrinkage behaviour of compacted clays, Geotechnical and Geological Engineering, 26(3), 289-298.

5) Mitchell J. K. and Soga, K. (2005). Fundamentals of soil behavior, $3^{\text {rd }}$ edition, Wiley, New York

6) Shariatmadari, N., Salami, M. and Karimpour, M.F. (2011). Effect of inorganic salt solutions on some geotechnical properties of soil bentonite mixtures as barriers, International Journal of Civil Engineering, 9 (2), 103-110.

7) Shirazi S.M., Wimat, S., Kazama, H., Kuwano, J. and Shaaban M.G. (2011). Salinity effect of swelling characteristics of compacted bentonite, Environment Protection Engineering, 37(2), 65-74.

8) Sridharan, A. and Jayadeva, M.S. (1982). Double layer theory and compressibility of clays, Geotechnique, 32(2), 133-144.

9) Thammathiwat, A. and Chimoye, W. (2010). Effect of permeant liquid on the swell volume and permeability of geosynthetic clay liners, Electronic Journal of Geotechnical Engineering, 15, 1183-119. 